\title{
BMJ Open Quality Improving preoperative haemoglobin using a quality improvement approach to treat iron deficiency anaemia
}

Rhona CF Sinclair, Kate E Duffield, Jane H de Pennington

To cite: Sinclair RCF, Duffield KE, de Pennington JH. Improving preoperative haemoglobin using a quality improvement approach to treat iron deficiency anaemia. BMJ Open Quality 2020;9:e000776. doi:10.1136/ bmjoq-2019-000776

Received 24 July 2019 Accepted 12 November 2019

\section{ABSTRACT}

Optimising preoperative haemoglobin $(\mathrm{Hb})$ before elective surgery is recommended by the National Institute of Clinical Excellence. We have used a quality improvement (QI) approach to treat iron deficiency anaemia in patients presenting to the preoperative assessment clinic (PAC) before major elective oesophagogastric surgery. Through a series of three QI cycles, we have treated iron deficiency, improved preoperative haemoglobin $(\mathrm{Hb})$ and reduced the rate of postoperative blood transfusion. Our methods have included the early diagnosis of iron deficiency at the PAC attendance, the development and implementation of a new clinical guideline on the treatment of preoperative anaemia and the introduction of a one-stop clinic facilitating same-day treatment with intravenous iron, where appropriate, in conjunction with comprehensive preoperative assessment. The incidence of severe preoperative anaemia $(\mathrm{Hb}<100 \mathrm{~g} / \mathrm{L})$ has fallen from $10 \%$ in 2014 to $1.6 \%$ in 2018 . The overall incidence of preoperative anaemia (defined as $\mathrm{Hb}<130 \mathrm{~g} / \mathrm{L}$ by international consensus statement) has reduced from $57.9 \%$ in 2014 to $43.9 \%$ in 2018 . Blood transfusion rate has declined from $16 \%$ to $6.5 \%$ of patients between 2014 and 2018. In 2018, none of the patients who required a postoperative blood transfusion presented to theatre with preoperative anaemia, a significant change from prior to the interventions. There has been a reduction of $63 \%$ in the number of units transfused. The project has successfully optimised these patients, leading to improved preoperative $\mathrm{Hb}$ and reduced use of blood transfusion.

\section{PROBLEM}

This article describes a quality improvement (QI) project improving care for patients undergoing elective oesophagogastric surgery; our unit performs approximately 120 oesophagogastric resections each year. The project has been conducted over 4 years in a large teaching hospital managing a mixed patient cohort within a busy preoperative assessment clinic (PAC) (>12000 patients/ annum). The project was led by the preoperative assessment team, with the support of members of the wider multidisciplinary team at the Royal Victoria Infirmary, Newcastle upon Tyne; ward staff and specialist nurses managing this group of patients have been integral to the success of this initiative.
In 2014, a gap analysis of the many facets of patient blood management $\left(\mathrm{PBM}^{1}\right)$ was conducted within preoperative assessment and surgical pathways as part of a larger trustwide gap analysis to assess our compliance with PBM, coordinated by our transfusion committee. This collection of audits was led by the author (RS) and addressed blood transfusion, transfusion triggers, cell salvage, blood conservation techniques, use of tranexamic acid and all other facets of PBM pertaining to the surgical pathway. The most notable area for improvement highlighted from this work was preoperative anaemia: it was demonstrated from data collection that there was a high incidence of anaemia in patients attending for gastrointestinal surgery (upper gastrointestinal and colorectal surgery), which was not being actively managed preoperatively. This patient group is known to have a high incidence of iron deficiency anaemia. ${ }^{2}$

The primary objective was therefore to treat preoperative iron deficiency anaemia before major surgery, focusing on patients undergoing gastro-oesophageal surgery, in line with the principles promoted by the PBM initiative. ${ }^{1}$ The secondary objective was to reduce the number of blood transfusions for this group of patients, as a consequence of treating iron deficiency.

\section{BACKGROUND}

Optimising preoperative $\mathrm{Hb}$, including the treatment of iron deficiency anaemia, is recommended before elective surgery. ${ }^{3-6}$ Recently, this has been driven by the publication of National Institute for Clinical Excellence (NICE) Quality Standards for Transfusion, ${ }^{7}$ which state that patients with iron deficiency anaemia who are having surgery should be offered iron supplementation before and after surgery. ${ }^{7}$ The NHS and Department of Health PBM initiative has served to promote a multidisciplinary, evidence-based approach to optimise best practice in detecting and managing preoperative anaemia. ${ }^{18}$ 
NICE states that iron supplementation can reduce the need for blood transfusion and avoid the serious risks that are associated with transfusion. ${ }^{7}$ Further, NICE proposes that hospital length of stay and cost to the NHS may be reduced by this intervention. ${ }^{7}$ Perioperative blood transfusion is associated with an increased risk of postoperative morbidity and mortality in some surgical patients. ${ }^{9} 10$

The incidence of anaemia is high in the elective surgical population, between $30 \%$ and $40 \%$, depending on diagnostic criteria and the population studied. ${ }^{911} 12$ Anaemia is independently associated with an increased risk of 30-day mortality and morbidity in patients having major non-cardiac surgery. ${ }^{913}$ This effect is demonstrated in both mild-moderate and severe anaemia. Furthermore, the addition of a second risk factor (respiratory, cardiac disease, diabetes and sepsis) in combination with anaemia further increases the adjusted OR for 30-day morbidity and mortality. ${ }^{9}$ Preoperative anaemia is also associated with increased postoperative blood transfu$\operatorname{sion}^{11}$; however, as surgery has evolved, the requirements for transfusion have decreased in many specialities, resulting in fewer transfusions. Nonetheless, a higher starting preoperative $\mathrm{Hb}$ may avoid the requirement for postoperative blood transfusion in patients who might otherwise have undergone this were they were anaemic preoperatively. ${ }^{14}$

The consensus guidance document published by Muñoz et al in 2017 outlines a summary guideline for improved clinical practice in this area.$^{15}$ This expert group recommends a pathway of anaemia management that begins before surgery and manages the patient through to successful recovery and discharge. The group recommends that this should be considered for all patients who are at risk of moderate to high blood loss, defined as $>500 \mathrm{~mL}^{15}$

\section{MEASUREMENT}

Data for each stage of analysis during this project were collected from the same sources. The reproducible population to be studied was defined at the outset as those patients undergoing major oesophagogastric cancer resections whose management and outcomes are recorded on the local oesophagogastric cancer database. At each stage of analysis, the details for patients undergoing surgery during a 6-month period were extracted from the database. The results of blood investigations were retrieved from the local electronic record system and blood transfusion data sourced from the blood transfusion laboratory local database, which records all blood products administered within the trust. The data were thus reliable and valid.

Our project design was pragmatic, and while it is not possible to fully exclude confounding factors that may have influenced the rate of transfusion, there were no significant changes to other aspects of the patients' perioperative and surgical care during the intervention period.
The following definitions describe the measured data for each audit cycle:

Presenting $\mathrm{Hb}$ and ferritin: the $\mathrm{Hb}$ concentration and ferritin level measured at the first attendance at the PAC.

Preoperative $\mathrm{Hb}$ : the $\mathrm{Hb}$ concentration measured 24 hours before surgery, or where this was unavailable on the date closest to surgery within the preceding 7 days.

Discharge $\mathrm{Hb}$ : the last measured $\mathrm{Hb}$ before discharge of the patient from the hospital after the major surgery episode.

Units of blood transfused: units of red cells transfused within the perioperative period and before discharge from the hospital during the major surgery episode (ie, intraoperative and postoperative transfusions).

\section{Baseline data (2013-2014)}

The baseline preoperative $\mathrm{Hb}$ measured for the group had a median of $125.4 \mathrm{~g} / \mathrm{L}$ (range $77-171 \mathrm{~g} / \mathrm{L}$ ).

During this baseline audit, anaemia was defined as $\mathrm{Hb}<120 \mathrm{~g} / \mathrm{L}$ for women and $\mathrm{Hb}<130 \mathrm{~g} / \mathrm{L}$ for men. This incidence of anaemia using these criteria was $40.9 \%$. The incidence of anaemia, as subsequently defined by the Munoz et al consensus statement $(\mathrm{Hb}<130 \mathrm{~g} / \mathrm{L}$ for all patients), was $58 \%$ at baseline.

Severe preoperative anaemia $(\mathrm{Hb}<100 \mathrm{~g} / \mathrm{L})$ was observed in $10 \%$ of patients.

Postoperatively, 33 units of blood were transfused to 14 patients (16\% of patients): most of this blood was given more than 7 days after surgery.

As the project evolved, we were able to collect data additional to the baseline dataset, including presenting $\mathrm{Hb}$ and ferritin, and discharge $\mathrm{Hb}$.

\section{DESIGN}

We designed an approach to identify and treat iron deficiency anaemia that was minimally disruptive to the care pathways of this group of patients. We were conscious that these patients attend a large number of hospital appointments while they have a 'work-up' of their cancer treatment plan. Rather than add to the burden of appointments, we realised that this presented several potential opportunities to treat patients (while they attended other appointments at the hospital). Thus, our intervention was delivered within the structure of the current care pathway. We used the multiple hospital appointments attended in their work-up as opportunities for delivery of treatment interventions.

Each patient presenting to the preoperative assessment service is assessed early within the cancer pathway (before final multidisciplinary team (MDT) decision making) and then has a second updated assessment in the 2 weeks before major surgery. The pathway is designed in this way to accommodate early diagnosis and management, which can contribute to MDT discussion, provide an opportunity to address modifiable risk factors and enable review 
following the physiological insult of neoadjuvant chemotherapy ( $70 \%$ of this patient group underwent neoadjuvant chemotherapy prior to surgery). In addition to the other investigations performed at this initial assessment, $\mathrm{Hb}$ and ferritin were measured and interpreted by the consultant anaesthetist in the PAC.

The decision to treat anaemia was based on locally agreed $\mathrm{Hb}$ and ferritin thresholds (see figure 1). It will be noted that these differ from the threshold values recommended more recently ${ }^{15}$; this local pathway was novel and exploratory and predated consensus guidance.

In the early stages of the project, the intervention was managed by the consultant anaesthetist who reviewed each patient and the oesophagogastric specialist nursing staff. The specialist nurses coordinated the administration of intravenous iron for patients while they attended other appointments on the day case ward, after instructions from the anaesthetist. The key team members at this stage were two consultant anaesthetists and two specialist nurses.

\section{STRATEGY}

\section{Improvement cycle 1 (2015)}

$\mathrm{Hb}$ and ferritin were measured at the PAC and interpreted by a consultant anaesthetist. The decision to treat iron deficiency was based on locally agreed $\mathrm{Hb}$ and ferritin thresholds (see figure 1); it will be noted that these differ from the threshold values recommended more recently. ${ }^{15}$ The primary intervention in this first QI cycle was the prescription and administration of $1 \mathrm{~g}$

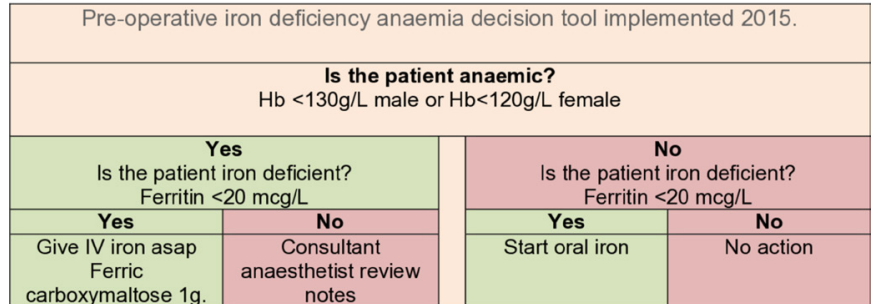

Figure 1 QI cycle 1 decision tool.

of intravenous ferric carboxymaltose to patients with $\mathrm{Hb}<120 \mathrm{~g} / \mathrm{L}$ (female) or $<130 \mathrm{~g} / \mathrm{L}$ (male) and ferritin $<20$ $\mu \mathrm{g} / \mathrm{L}$. This was administered on the hospital day case ward: commonly, the infusion was completed during an appointment when the patient was attending for other investigations. Appointments were organised by the specialist nurses and coordinated with other attendances.

\section{Improvement cycle 2 (January 2018)}

Analysis of $\mathrm{Hb}$ and blood transfusion data over the period of June-November 2017 was performed as described previously. This time period was chosen as it allowed enough time for the clinical team to have become familiar with, and thus consistently implement, the cycle 1 intervention. An improvement in preoperative $\mathrm{Hb}$ concentration and a decrease in the number of units of blood transfused were demonstrated (see table 1).

On the basis of this evidence of improvement, a second QI cycle was commenced.

Table 1 Characteristics of patients included in each timed data collection at baseline (2013-2014) and after PDSA cycle 1 (2017) and cycle 3 (2018)

\begin{tabular}{llll}
\hline & December 2013-June 2014 & February-July 2017 & June-November 2018 \\
\hline $\mathrm{n}$ & 88 & 62 & 61 \\
\hline Age (years) & $66(33-83)$ & $67(26-86)$ & $72(44-88)$ \\
\hline M:F & $61: 27$ & $40: 21$ & $43: 18$ \\
\hline Surgery & & & 37 \\
$\quad$ STO & 33 & 34 & 14 \\
$\quad$ STG & 32 & 13 & 7 \\
$\quad$ TG & 12 & 11 & 0 \\
$\quad$ Wedge resection & 2 & 3 & 2 \\
$\quad$ Other & 4 & 1 & $2(2.0-4.5)(0-240)$ \\
\hline Length of stay, critical care (days $\left.{ }^{\star}\right)$ & $1(0-2)(0-14)$ & $2(0-3)(0-24)$ & $10(8.0-15.5)(3-40) \dagger$ \\
\hline Length of say in the hospital (days) & $11.5(9-16)(0-47)$ & $9.5(7-16)(3-167)$ & 0 \\
\hline In-hospital mortality & 1 & 2 & $132(117-144)(77-179)$ \\
\hline Presenting Hb at PAC (g/L) & - & $122(122-146)(88-159)$ & $130(120-140)(95-174)$ \\
\hline Preoperative Hb (g/L) & $125.4(116-136)(77-171)$ & $131(119-137)(98-159)$ & 13 \\
\hline
\end{tabular}

Values are median (IQR) (range).

${ }^{*}$ Critical care admission length of stay is calculated from the number of calendar days or part days that the patient was cared for in critical care.

†One patient remains an inpatient at the time of writing (240 days), awaiting home ventilator support for discharge.

$\mathrm{Hb}$, haemoglobin; PAC, preoperative assessment clinic; PDSA, plan-do-study-act; STG, subtotal gastrectomy; STO, two-stage subtotal oesophagectomy; TG, total gastrectomy. 
Cycle 2 Interventions.

- Introduction of a new guideline describing the management of patients with pre-operative anaemia.

- Change in intravenous iron product to iron maltoside 1000 , in order to facilitate the prescription of a single optimised preoperative dose of intravenous iron, administered during a single attendance. Dose prescribed: $20 \mathrm{mg} / \mathrm{kg}$ Iron maltoside1000.

- Change in trigger ferritin serum concentration to $<30 \mathrm{microg} / \mathrm{L}$. Change in definition of anaemia to $\mathrm{Hb}<130 \mathrm{~g} / \mathrm{L}$ for male and female patients.

- Clear pathway of care for identification, prescription and administration of product utilising day case ward facilities.

Figure 2 Interventions in cycle 2.

Cycle 2 comprised the following composite bundle of improved interventions (see figure 2).

First, we decided to change our intravenous iron product in order to facilitate a single optimal dose of intravenous iron to be given in a single day case attendance. We are a tertiary centre covering a large geographical area. The previous intervention consisted of a standardised capped dose of intravenous iron (ferric carboxymaltose $1 \mathrm{~g}$ ). In order to give a higher dose of iron (to patients with very low $\mathrm{Hb}$ or high body weight), a second attendance for day case infusion would have been required: this was perceived as inconvenient to patients and also complicated our patient pathways. Thus, we changed our iron prescription to iron isomaltoside 1000, allowing a weight-based optimised dose of iron to be given in a single attendance.

Second, in conjunction with hospital pharmacists, we developed and introduced a trust-wide guideline on the treatment of iron deficiency anaemia in the perioperative setting. This guideline directs the identification, prescription and safe administration of intravenous iron to adult patients and also acts as the prescription and record of administration.

Following the publication of international consensus guidelines, ${ }^{15}$ we changed the definition of anaemia to $\mathrm{Hb}<130$ for all patients, and the ferritin threshold was raised from $<20$ to $<30$.

A final change was to the arrangements for the administration of intravenous iron. Following discussion with the manager of the day case ward, it was agreed that the nursing team in PAC could liaise directly with the ward team to book appointments for infusions, removing this workload from the specialist nurses.

\section{Improvement cycle 3 (September 2018)}

The intervention in the third cycle was introduced before the full analysis of cycle 2 interventions. Increased consultant and nurse staffing within our preoperative assessment service allowed the introduction of a 'one-stop, same-day' anaemia treatment initiative for all patients undergoing major gastrointestinal surgery. While we recognised that we were making a further change without having fully studied the impact of the previous interventions, it was not felt that this would significantly affect our primary and secondary outcomes, but had the potential to immediately improve the patient experience.
Thus, in September 2018, we introduced point-of-care (POC) Hb testing to our PAC. This was done to facilitate the ability to diagnose and treat preoperative anaemia in high-risk patients at a single hospital attendance. When patients attending our high-risk clinics (including the oesophagogastric patient population) arrive in the clinic, they have a POC $\mathrm{Hb}$ measurement (Hemocue $\mathrm{Hb} 201$, Angelholm, Sweden). If the POC measurement demonstrates an $\mathrm{Hb}$ of $<130 \mathrm{~g} / \mathrm{L}$, then the blood tests for that individual are taken immediately and sent as priority to the laboratory: this enables us to retrieve the results for these patients urgently and to make a decision about treatment based on $\mathrm{Hb}$, ferritin and CRP. ${ }^{15}$ Given that this patient group is predominantly undergoing treatment for malignant and inflammatory conditions, ferritin, as an acute phase protein, may be elevated; where the diagnosis of iron deficiency anaemia cannot be excluded by this first line set of tests, we have the opportunity to add appropriate further blood test orders if required. At this point, approximately 2 hours after the first POC Hemocue test, we can add iron studies (transferrin saturations \pm iron and total iron binding capacity) as clinically indicated to the laboratory order without repeating blood sampling. The urgent processing of bloods in anaemic patients enables us to diagnose iron deficiency rapidly and to deliver our intravenous iron intervention during the clinic attendance. Where the blood results demonstrate macrocytosis, $\mathrm{B}_{12}$ and folate concentrations can also be added to the initial blood sample during the same clinic visit.

\section{RESULTS}

The characteristics displayed in table 1 confirm that the audit sample selected via the database of major operations was comparable between the three time points; there are more cases at baseline, possibly due to a 7-month sample or natural variation. The age, gender and types of surgery are comparable.

\section{Incidence of preoperative anaemia}

The baseline audit reported a wide range of preoperative $\mathrm{Hb}$ concentrations: median 125.5 (range $77-171) \mathrm{g} / \mathrm{L}$ for this population in 2013-2014. An increase in median preoperative $\mathrm{Hb}$ and a reduction in the range of values is seen after QI cycle 1 in 2017 (131 (range 98-159) g/L) and sustained into 2018 after QI cycles 2 and 3 (130 (range 95-174) g/L) (see table 1). There is a narrowing of the range of preoperative $\mathrm{Hb}$ after the intervention.

Severe preoperative anaemia $(\mathrm{Hb}<100 \mathrm{~g} / \mathrm{L})$ was recorded for $10 \%$ of patients in 2014. This has been reduced to $1.6 \%$ in 2017; the change is sustained into 2018 (see figure 3).

The incidence of anaemia as defined by the Munoz et al consensus statement $(\mathrm{Hb}<130 \mathrm{~g} / \mathrm{L})$ was $58 \%$ in 2014 , falling to $44 \%$ in 2017 and $44 \%$ in 2018 .

\section{Identifying anaemic patients and interventions in PAC}

The number of patients presenting to the PAC with anaemia is comparable between 2017 and 2018. No data 


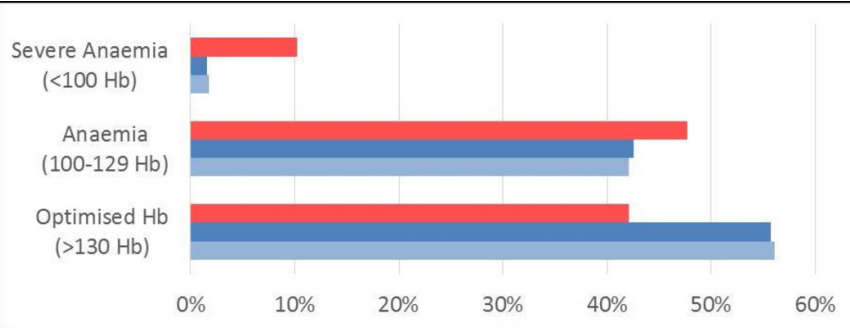

Figure 3 Preoperative $\mathrm{Hb}$ concentration measured at baseline (2013-2014, shown in red), after cycle 1 (2017, shown in dark blue) and after cycle 3 (2018, in light blue). Hb, haemoglobin.

are available for 2014 as this did not form part of the baseline audit; rather, the intervention was instigated based on these data. However, in 2018, the proportion of patients with iron deficiency anaemia at presentation was higher than that in 2017 ( $24.6 \%$ vs $14.5 \%$, respectively).

In 2018, 20/61 patients received intravenous iron. This was given to 15 patients with iron deficiency anaemia defined within the guideline as $\mathrm{Hb}<130 \mathrm{~g} / \mathrm{L}$ and ferritin $<30 \mu \mathrm{g} / \mathrm{L}$, as seen in table 2. Six further infusions were prescribed to patients where ferritin $>30 \mu \mathrm{g} / \mathrm{L}$ and other iron studies confirmed iron deficiency, or to patients with non-anaemic iron deficiency $(\mathrm{Hb}>130 \mathrm{~g} / \mathrm{L}$, ferritin<30 $\mu \mathrm{g} / \mathrm{L})$ (see table 2 ).

The change in $\mathrm{Hb}$ due to the iron infusion is difficult to describe within this complicated treatment pathway. There is a small group of patients who received intravenous iron within 4 weeks of surgery; in this group (median time between infusion and surgery of 23 days), the $\mathrm{Hb}$ increased by a median of $10 \mathrm{~g} / \mathrm{L}$ (range $2-19 \mathrm{~g} / \mathrm{L}$ ). The

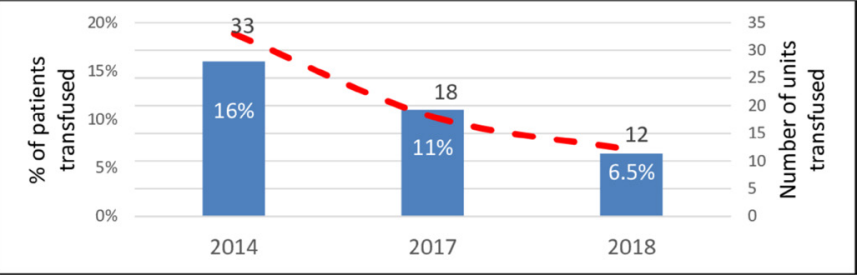

Figure 4 Reduction in blood usage demonstrated during the QI project between baseline usage (2013-2014) and cycle 1 (2017) and cycle 3 (2018). The number of units transfused is represented by a dashed red line. The proportion of patients receiving blood is recorded in blue bars.

majority of patients had a longer time period between intravenous iron and surgery (median 124 days, due to neoadjuvant chemotherapy). In this group, the median increase in $\mathrm{Hb}$ was $11 \mathrm{~g} / \mathrm{L}$, though the range was -21 to $+55 \mathrm{~g} / \mathrm{L}$. (All the possible clinical events that could occur within this time frame are not documented or described.)

\section{Blood transfusions (within 30 days of surgery)}

The proportion of patients undergoing postoperative blood transfusion has declined from $16 \%$ at baseline (2014) to $6.5 \%$ in 2018 (figure 4). Similarly, the number of units of red cells used by this population has declined from 33 units to 18 and 12 units in 2017 and 2018 respectively: this is a reduction of $63 \%$. Analysis of timing of the transfusion confirms that while intraoperative transfusion remains infrequent and unpredictable, the use of blood in the period of 8-21 days postsurgery has significantly reduced. Patients who remain in the hospital (and receive blood) beyond this time have significantly prolonged

Table 2 Analysis of presenting blood investigations done within anaemia pathways in preassessment clinic within PDSA cycle 1 (2017) and cycle 3 (2018)

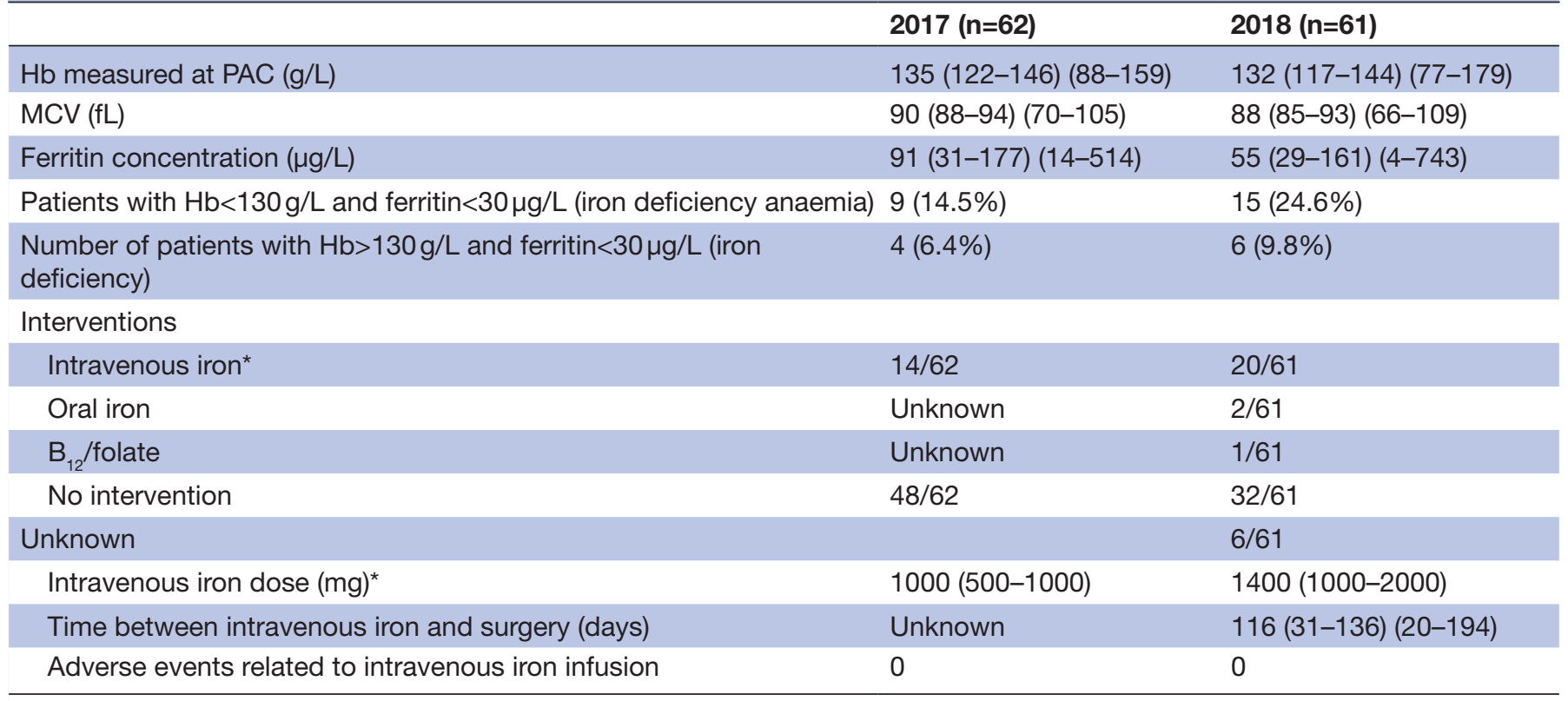

Values are median (IQR) (range) or number (proportion).

*In 2017, this was $1 \mathrm{~g}$ ferric carboxymaltose; in 2018, this was $20 \mathrm{mg} / \mathrm{kg}$ iron isomaltoside.

$\mathrm{Hb}$, haemoglobin; MCV, Mean corpuscular volume; PAC, preoperative assessment clinic; PDSA, plan-do-study-act. 
stays (median length of stay after oesophagectomy is 12 days) and had significant complex postoperative complications.

On inspection of the individual patients who underwent blood transfusions, we can demonstrate that the blood transfusions in 2014 were principally given to patients with anaemia. Indeed, in 2014, 12/14 patients who underwent blood transfusions were anaemic preoperatively by consensus definition: 5 of these patients had a preoperative $\mathrm{Hb}$ of $<95 \mathrm{~g} / \mathrm{L}$. In 2017, three patients requiring blood transfusion had preoperative anaemia (Hb 127, 114, $98 \mathrm{~g} / \mathrm{L}$ ), and in 2018, only one patient had preoperative anaemia $(\mathrm{Hb} 95 \mathrm{~g} / \mathrm{L})$.

\section{LESSONS AND LIMITATIONS}

This QI project has demonstrated the ability of a simple preoperative anaemia pathway to address the aims of treating iron deficiency anaemia before major surgery and reducing the use of blood transfusions postoperatively. We have presented our real-world experience and acknowledge that there are limitations to the outcomes and data available.

The patients managed with this pathway presented with a high incidence of anaemia similar to that previously reported for groups of patients with cancer and surgical patients presenting for major non cardiac surgery. ${ }^{2}{ }^{11} 16-18$ Gastrointestinal patients have a combination of pathophysiological mechanisms that lead to this high incidence of iron deficiency anaemia and complicate their management: they can present with chronic and/or acute blood loss, poor intake of iron (dysphagia), inflammatory hepcidin-mediated inhibition of intestinal absorption and inhibition of absorption by gastric antacids and proton pump inhibitors. ${ }^{19}$ Each of these factors will have been present within our populations and will have contributed to iron deficiency and progressive anaemia.

The use of intravenous iron as part of a PBM programme is recommended by perioperative and oncological consensus guidelines to treat iron deficiency and functional anaemia (due to cancer and inflammation). ${ }^{1518} 19$ In our clinic, this therapy has reduced the proportion of patients presenting to theatre with a severe anaemia $(\mathrm{HB}<100 \mathrm{~g} / \mathrm{L})$ from $10 \%$ to $1.6 \%$. During the time period covered by this QI project, there were no other PBM changes instituted for this group of patients: surgical approach and intraoperative blood loss remained consistent, and oncological treatment was unchanged. We believe that the reduction in blood transfusion and prevention of severe preoperative anaemia can be attributed to the preoperative anaemia pathway.

The data presented from 2018 show that improvements from treating iron deficiency anaemia have been sustained; moreover, our pathway was incorporated into clinical care without additional resource or inconvenience to patient pathways. We have introduced our anaemia pathway to the early stages of our patient pathway in order to afford the greatest duration of time for haematopoesis; as a consequence, we have also treated patients who do not ultimately present to the operating theatre. These patients will still benefit from treatment of iron deficiency anaemia. ${ }^{18} 2021$ The introduction of POC $\mathrm{Hb}$ testing has facilitated diagnosis and treatment of iron deficiency anaemia during a single preassessment clinic attendance. This has streamlined the patient pathway, requiring fewer hospital attendances.

The number of units of blood transfused postoperatively has reduced by $64 \%$ since this QI project was commenced. Preoperative anaemia is associated with transfusion $^{11}$; avoiding blood transfusion is desirable to reduce morbidity and the potentially harmful risks of transfusion. ${ }^{722}$ We accept that we cannot prevent all transfusions with a preoperative intervention: there will undoubtedly remain patients who require blood during complex surgery or prolonged critical care stay.

Our anaemia pathways are also used for other patient groups presenting to the preoperative assessment service. We use the perioperative guideline for all patients in the clinic who meet inclusion criteria to enter the anaemia pathway, that is, operations that are commonly associated with the potential for $>500 \mathrm{~mL}$ blood loss. The QI project has thus improved care for a wider patient population in our clinic. Naturally, there are also other less tangible benefits that have arisen from this initiative. Awareness of iron deficiency anaemia and the ability and importance of optimising this preoperatively has increased both within and beyond the PAC during the time that this project has been running. It is difficult to quantify the benefits that word of mouth and the presence of our guideline have had on improving standards of practice.

There are limitations to the interpretation of the data presented. This is a 'real-life experience' of a clinical pathway and not a research study. We were unable to describe compliance with the pathway in 2017. Similarly, we do not have $\mathrm{Hb}$ measurements taken at standardised time points after intravenous iron infusion, making comparison of response difficult. There will have been many variations in care and in the events experienced by these patients. Our heterogeneous clinical population has multiple pathophysiologies driving their anaemia, as mentioned previously. The improvements described here have been effected despite the heterogeneous population.

Lastly, we cannot expect to eliminate preoperative anaemia completely in patients presenting for surgery for all of the reasons described. A QI intervention that is applied during preoperative work-up will not influence intraoperative blood loss or the occasional significant postoperative bleed or prevent the transfusions given to a patient who develops multiple postoperative problems culminating in multiorgan failure on critical care. These transfusions must be accepted. Similarly, there are patients within our heterogeneous population who are anaemic but do not have iron deficiency. Our pathway promotes individualised management plans for these patients directed by the PAC consultant, but some of these anaemias will not be correctable due to the causative 
pathology. However, the evidence presented here demonstrates that if applied preoperatively, this intervention to identify and treat iron deficiency anaemia can significantly improve preoperative $\mathrm{Hb}$ and reduce the overall transfusion rate.

Our QI project has evolved over time in response to our observations. Analysis of discharge $\mathrm{Hb}$ in our latest data capture has revealed that despite a proactive preoperative anaemia pathway, our patients are discharged from the hospital anaemic (median $\mathrm{Hb} 105 \mathrm{~g} / \mathrm{L}$ ). We can confirm this finding in the previous cohorts by retrospectively adding discharge $\mathrm{Hb}$ concentrations for the 2014 and 2017 cohorts. The NICE quality statement promotes postoperative management of iron deficiency anaemia, and a recent publication confirms the high rates of rehospitalisation and 6-month mortality rate in patients discharged from the hospital with moderate anaemia. ${ }^{723}$ Consensus guidance is available to direct our fourth cycle of QI. ${ }^{24}$

\section{CONCLUSION}

Our QI approach to treat preoperative iron deficiency anaemia has been successful in a heterogeneous 'realworld' clinical situation. This sustainable change could be replicated in other preoperative assessment services and to this end we feel that this work should be made available for others to learn from. The work has been disseminated and presented locally; and won local QI prizes.

To sustain this improvement we must continue to promote the use of our clinical guideline both in our PAC and more widely for surgical patients throughout the hospital where it is applicable. We will continue to audit our results. Currently we record all patients who have been referred for intravenous iron through our pathway: we have introduced it to other surgical patient groups managed in the PAC. In 2018, a broad mix of patients were managed and audit data showed that the indications for treatment were met and infusions were administered appropriately. Continuing to complete this feedback loop will sustain our intervention and direct its ongoing development.

There is a lot of interest currently in this area of work, and the quality statement issued by NICE has driven hospitals to develop this area of practice. Our service has demonstrated improvement, and we consider it to have been a valuable and successful project.

Acknowledgements $A$ large and diverse group of colleagues has been involved in the success of this project. Thanks are extended to E McCone, A Cant, L Bell, $C$ Sedgwick, M Bliss, A Sharpe, L Mossetig, H Jaretze, C Lovett, A Green, A Baird, J Prentis, R Bird, M Callaghan, S Metcalfe, B Goodman, H Dawson, K Naru, E Pugh, C Rimmer, K Roberts and C Gillan.

Contributors RCFS planned the study. KED and RCFS collected the data and developed the QI cycles. RCFS and KED implemented the initial cycle 1 intervention. JHdP and RCFS developed and implemented the new clinical guideline. All authors contributed to the manuscript and approved the final draft.

Funding This work was unfunded but did receive financial support from Pharmacosmos UK to enable publication. Pharmacosmos UK had no role in project design, collection, analysis or interpretation of data, writing of the report, or in the decision to submit the paper for publication.
Competing interests RCFS has received an honorarium from Pharmacosmos UK Ltd.

Patient consent for publication Not required.

Provenance and peer review Not commissioned; externally peer reviewed.

Data availability statement All data relevant to the study are included in the article.

Open access This is an open access article distributed in accordance with the Creative Commons Attribution Non Commercial (CC BY-NC 4.0) license, which permits others to distribute, remix, adapt, build upon this work non-commercially, and license their derivative works on different terms, provided the original work is properly cited, appropriate credit is given, any changes made indicated, and the use is non-commercial. See: http://creativecommons.org/licenses/by-nc/4.0/.

\section{REFERENCES}

1 JPAC. Patient blood management, 2013. Available: http://www.tran sfusionguidelines.org.uk/uk-transfusion-committees/national-bloodtransfusion-committee/patient-blood-management

2 Muñoz M, Laso-Morales MJ, Gómez-Ramírez S, et al. PreOperative haemoglobin levels and iron status in a large multicentre cohort of patients undergoing major elective surgery. Anaesthesia 2017;72:826-34.

3 American Society of Anesthesiologists Task Force on Perioperative Blood Management. Practice guidelines for perioperative blood management: an updated report by the American Society of Anesthesiologists Task force on perioperative blood Management*. Anesthesiology 2015;122:241-75.

4 Mueller MM, Van Remoortel H, Meybohm P, et al. Patient blood management: recommendations from the 2018 Frankfurt consensus conference. JAMA 2019;321:983-97.

5 Kotzé A, Harris A, Baker C, et al. British Committee for standards in haematology guidelines on the identification and management of pre-operative anaemia. Br J Haematol 2015;171:322-31.

6 Kozek-Langenecker SA, Afshari A, Albaladejo P, et al. Management of severe perioperative bleeding: guidelines from the European Society of Anaesthesiology. Eur J Anaesthesiol 2013;30:270-382.

7 NICE. Nice publication. blood transfusion. quality standard, 2016 Available: nice.org.uk/guidance/qs138 [Accessed 15 Dec 2016].

8 www.nhsbt.nhs.uk/

9 Musallam KM, Tamim HM, Richards T, et al. Preoperative anaemia and postoperative outcomes in non-cardiac surgery: a retrospective cohort study. Lancet 2011;378:1396-407.

10 Moskowitz DM, McCullough JN, Shander A, et al. The impact of blood conservation on outcomes in cardiac surgery: is it safe and effective? Ann Thorac Surg 2010;90:451-8.

11 Fowler AJ, Ahmad T, Phull MK, et al. Meta-Analysis of the association between preoperative anaemia and mortality after surgery. Br J Surg 2015;102:1314-24.

12 Shander A, Knight K, Thurer R, et al. Prevalence and outcomes of anemia in surgery: a systematic review of the literature. Am J Med 2004;116:58-69.

13 Wu W-C, Schifftner TL, Henderson WG, et al. Preoperative hematocrit levels and postoperative outcomes in older patients undergoing noncardiac surgery. JAMA 2007;297:2481-8.

14 Spahn DR. Anemia and patient blood management in hip and knee surgery: a systematic review of the literature. Anesthesiology 2010;113:482-95.

15 Muñoz M, Acheson AG, Auerbach M, et al. International consensus statement on the peri-operative management of anaemia and iron deficiency. Anaesthesia 2017;72:233-47.

16 Aapro M, Österborg A, Gascón P, et al. Prevalence and management of cancer-related anaemia, iron deficiency and the specific role of i.v. iron. Ann Oncol 2012;23:1954-62.

17 Knight K, Wade S, Balducci L. Prevalence and outcomes of anemia in cancer: a systematic review of the literature. Am J Med 2004;116:11-26.

18 Aapro M, Beguin Y, Bokemeyer C, et al. Management of anaemia and iron deficiency in patients with cancer: ESMO clinical practice guidelines. Ann Oncol 2018;29:iv96-110.

19 Munting KE, Klein AA. Optimisation of pre-operative anaemia in patients before elective major surgery - why, who, when and how? Anaesthesia 2019;74:49-57.

$20 \mathrm{Ng} \mathrm{O}$, Keeler B, Simpson JA, et al. Feasibility of intravenous iron Isomaltoside to improve anemia and quality of life during palliative chemotherapy for esophagogastric adenocarcinoma. Nutr Cancer 2018;70:1106-17. 
21 Lima J, Gago P, Rocha M, et al. Role of intravenous iron in the treatment of anemia in patients with gastrointestinal tract tumors undergoing chemotherapy: a single-center, observational study. Int $J$ Gen Med 2018;11:331-6.

22 Whitlock EL, Kim H, Auerbach AD. Harms associated with single unit perioperative transfusion: retrospective population based analysis. BMJ 2015;350:h3037.
23 Roubinian NH, Murphy EL, Mark DG, et al. Long-Term outcomes among patients discharged from the hospital with moderate anemia: a retrospective cohort study. Ann Intern Med 2019;170:81-9.

24 Muñoz M, Acheson AG, Bisbe E, et al. An international consensus statement on the management of postoperative anaemia after major surgical procedures. Anaesthesia 2018;73:1418-31. 